\title{
Quantitative Detection of Chlamydia spp. by Fluorescent PCR in the LightCycler ${ }^{\circledR}$
}

BioTechniques 30:150-157 (January 2001)

\author{
J. Huang, F.J. DeGraves, D. \\ Gao, P. Feng, T. Schlapp ${ }^{1}$, and \\ B. Kaltenboeck \\ College of Veterinary Medicine, \\ Auburn University, Auburn, AL, \\ USA and ${ }^{1}$ Bayer AG, Animal \\ Health, Monheim, Germany
}

\section{INTRODUCTION}

Quantitative detection of bacteria of the obligately intracellular genus Chlamydia relies on the standard procedure of inoculating cells grown on coverslips or microwells with the suspended specimen, fixing the cells after 24-72 h, and microscopically enumerating chlamydial intracellular inclusions stained with fluorescent monoclonal antibody $(2,4,10)$. This method is cumbersome, requires experienced personnel, and is prone to subjective error. Few investigators have evaluated the labor-intensive competitive quantitative PCR as replacement of the cell culture method for quantification of chlamydiae $(1,2)$.

Advances in PCR instrumentation and use of fluorescent labels for detection of amplification products have facilitated several approaches to singletube real-time PCR quantification of input target copies. In particular, the LightCycler ${ }^{\circledR}$ (Roche Molecular Biochemicals, Indianapolis, IN, USA) format uses hot air to rapidly cycle PCRs loaded in glass capillaries while measuring fluorescence emitted from the reaction vessels $(13,14)$. This allows monitoring of the fluorescence emitted by a number of detection formats, including direct detection of the dsDNA product with specific dsDNA binding dyes $(5,13)$ and hybridization-based detection methods $(3,8,11,13)$.

Here, we report the adaptation of hot-start PCR methodology to the glass capillary format of the LightCycler. This was used for amplification and quantitative detection of as few as single copies of DNA of Chlamydia spp. by SYBR ${ }^{\circledR}$ Green fluorescence (Molecular Probes, Eugene, OR, USA) of the dsDNA product and by fluorescence resonance energy transfer (FRET) hybridization probes. These methods were compared to cell culture quantification of chlamydiae in concentrated chlamydial stock and in lung specimens from Chlamydia-infected mice. FRET quantitative PCR was 15 -fold more sensitive and more accurate than quantification of chlamydiae in cell culture.

\section{MATERIALS AND METHODS}

\section{Primers and Probes}

Primers and probes are shown in Table 1. The Chlamydia omp1 genusspecific PCR targeted the single-copy gene encoding the chlamydial major outer membrane protein. It used primers 191CHOMP and CHOMP271 $(6,7)$ to amplify a 287-293-bp DNA fragment of all chlamydial species, which was detected by the 520 -nm fluorescent emission of the dsDNA binding dye SYBR Green. The C. psittaci B577 omp 1-specific FRET PCR used the Chlamydia genus-specific primers 191CHOMP and CHOMP271 in combination with the Chlamydia ompl genus-specific anchor probe CHLANPR and the $C$. psittaci B577 omp1-specific probe B577PR (Synthegen, Houston, TX, USA). FRET PCRs specific for strains of other chlamydial species (Table 1) substituted the B577PR probe with an analogous fluorescein-labeled probe corresponding to the nucleotide sequence of the respective strain. CHLANPR was 5'-labeled with the dye LightCycler Red 640 (LCR640) and 3'-phosphorylated; B577PR was 3'-labeled with fluorescein. If both probes annealed simultaneously to the product, fluorescence energy emitted by B577PR was transferred to the adjacent LCR640 of CHLANPR, 


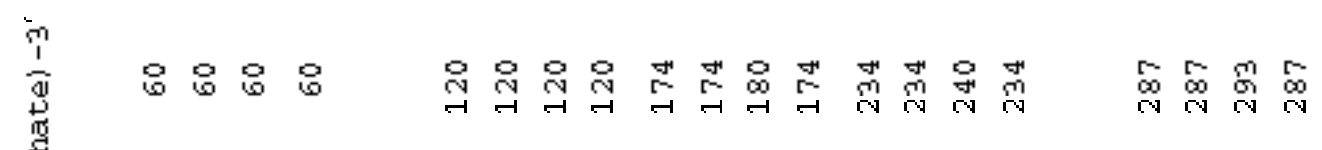

舜

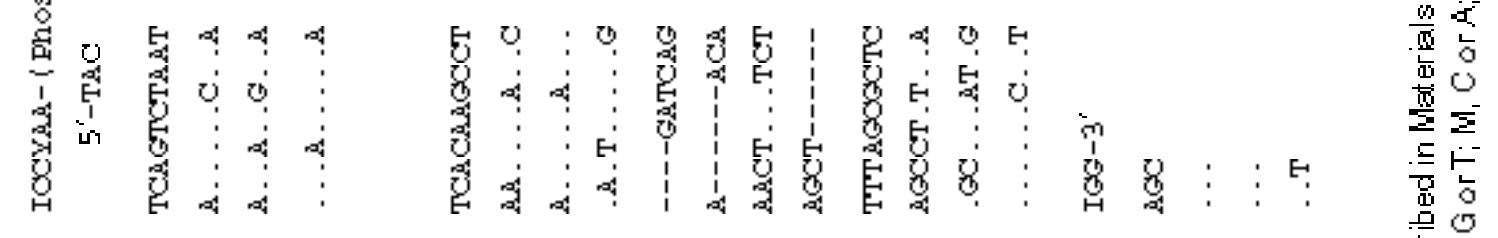

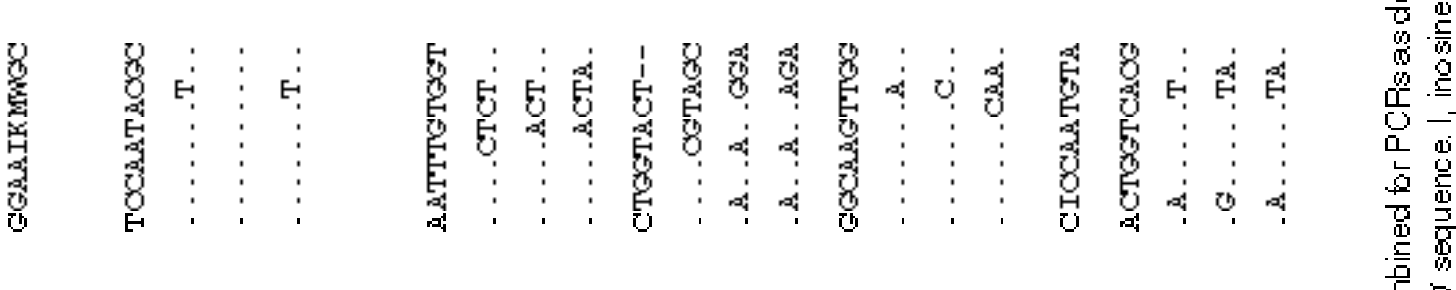

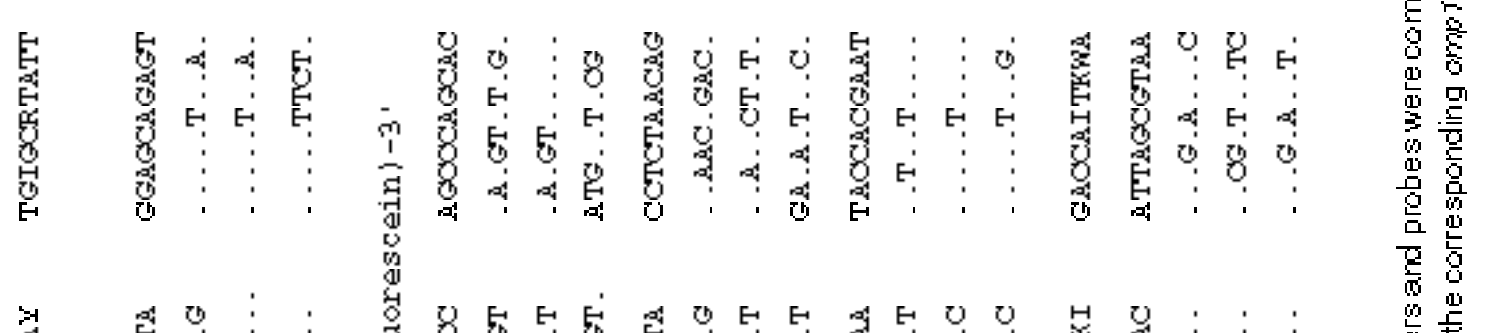

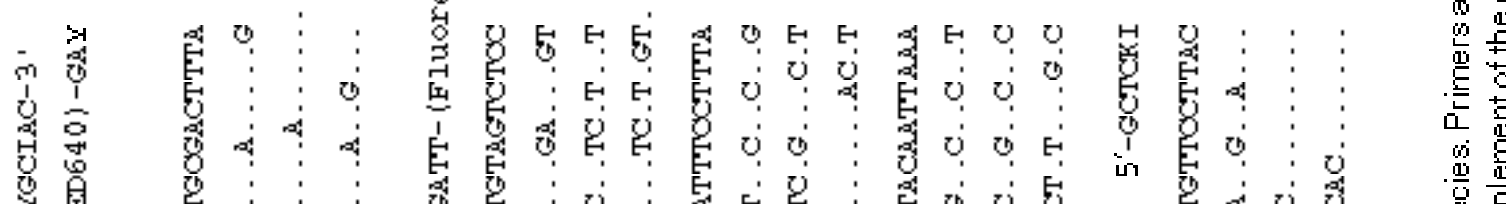

3

焉

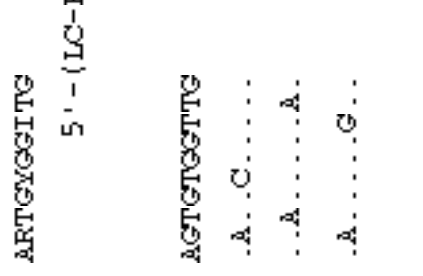

(3)

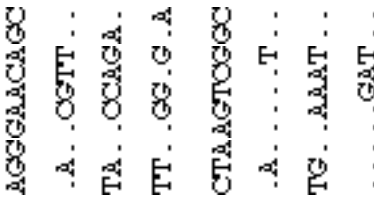

要

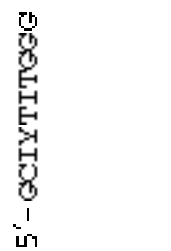

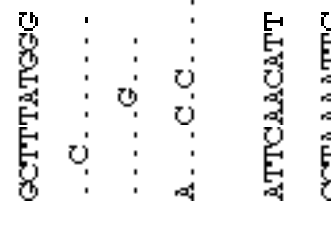

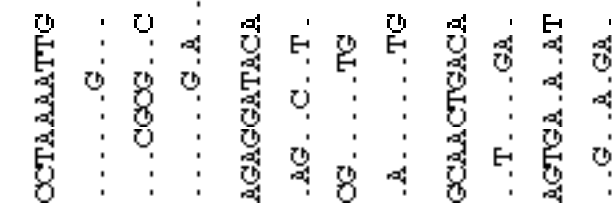

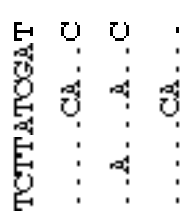

$\frac{3}{3}$

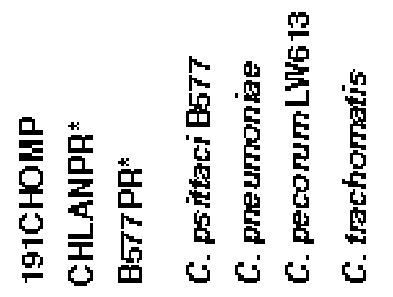
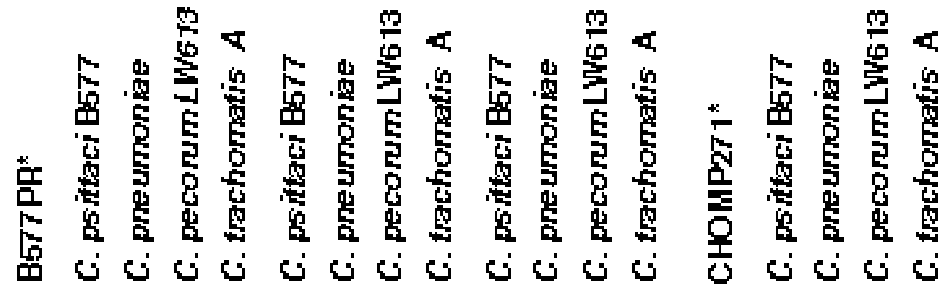

.

音

要

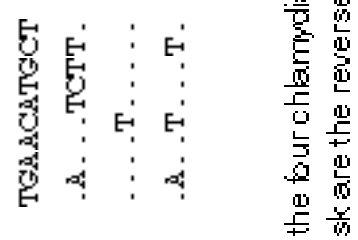

童

(ํ.

要

.

咅

㟧

寒

용ㅎㅁ

촣을

尊高容

要

昰焉要 
resulting in increased emission at 640 $\mathrm{nm}$. The ratio of $640 \mathrm{~nm}: 520 \mathrm{~nm}$ emission at the end of the annealing segment allowed for the most accurate product detection. The human COX-1 PCR used primers from a Human COX-1 Relative RT-PCR Kit, no. 5306 (Ambion, Austin, TX, USA) to amplify a 401-bp fragment of a linearized plasmid containing COX1 cDNA, which was added in known quantity to samples before DNA extraction. This allowed for calculation of the recovery of DNA after extraction and, thus, for absolute quantitative detection of chlamydial DNA in these samples.

\section{DNA Amplification and Detection}

All PCRs were performed in glass capillaries (Roche Molecular Biochemicals) in $20-\mu \mathrm{L}$ volumes, using $5 \mu \mathrm{L}$ sample DNA (10-250 ng total DNA) and $15 \mu \mathrm{L} 1.33 \times$ PCR mastermixture. The PCR buffer (20 mM Tris- $\mathrm{HCl}, \mathrm{pH}$ 8.4) contained $0.05 \%$ each Tween ${ }^{\circledR} 20$ and Nonidet ${ }^{\circledR}$ P-40 (NP40), $0.03 \%$ acetylated bovine serum albumin (BSA) (Roche Molecular Biochemicals), $200 \mu \mathrm{M}$ each dATP, dCTP, and dGTP, $600 \mu \mathrm{M}$ dUTP, $3 \mathrm{mM} \mathrm{MgCl}_{2}$, and $10 \mathrm{mM} \mathrm{KCl}$ (SYBR Green PCRs) or $4.5 \mathrm{mM} \mathrm{MgCl}_{2}$, and $50 \mathrm{mM} \mathrm{KCl}$ (FRET PCRs). In SYBR Green PCRs, the SYBR Green stock solution (Molecular Probes) was used at a dilution of 1:10000 (13). All primers were used at $1 \mu \mathrm{M}$ concentration, and FRET probes were used at $0.5 \mu \mathrm{M}$. Per $20-\mu \mathrm{L}$ reaction, $1 \mathrm{U}$ hot-start Platinum Taq DNA polymerase and $0.2 \mathrm{U}$ uracil-N-glycosylase (Life Technologies, Rockville, MD, USA) were used.

Standard reactions including negative controls contained 104_0 template molecules (chlamydial genomic DNA extracted from purified chlamydial elementary bodies or COX-1 plasmid template) in a background of $100 \mathrm{ng}$ re-extracted salmon sperm DNA (Life Technologies). Chlamydial DNA was quantified by the PicoGreen ${ }^{\circledR}$ fluorescent assay (Molecular Probes) and diluted according to a calculated mass of $1.37 \times 10^{-15} \mathrm{~g}$ per $C$. psittaci or $C$. pneumoniae genome.

A 2-min incubation at $50^{\circ} \mathrm{C}$ for activation of uracil-N-glycosylase (to prevent PCR product carryover) was followed by denaturation at $95^{\circ} \mathrm{C}$ for 1 min, then 50 cycles of $95^{\circ} \mathrm{C}$ for $0 \mathrm{~s}$, $53^{\circ} \mathrm{C}$ (all Chlamydia PCRs) or $59^{\circ} \mathrm{C}$ $(\mathrm{COX}-1)$ for $3 \mathrm{~s}$, followed by fluorescence acquisition in the FRET PCRs, or for $10 \mathrm{~s}$ in the SYBR Green format, followed by extension at $72^{\circ} \mathrm{C}$ for $15 \mathrm{~s}$ in all PCRs. For SYBR Green PCRs, single fluorescence acquisition in each cycle was specified $2^{\circ} \mathrm{C}-3^{\circ} \mathrm{C}$ below the melting temperature $\left(\mathrm{T}_{\mathrm{m}}\right)$ of the amplification product at $80^{\circ} \mathrm{C}$ (Chlamydia omp 1) or $87^{\circ} \mathrm{C}(\mathrm{COX}-1)$ after a $10-\mathrm{s}$ temperature equilibration. After cycling, melting curves of PCR products were acquired by stepwise increase of the temperature from $65^{\circ} \mathrm{C}$ to $95^{\circ} \mathrm{C}$ (SYBR Green PCRs) or from $45^{\circ} \mathrm{C}$ to $85^{\circ} \mathrm{C}$ (FRET PCRs).

\section{Quantitative Culture of Chlamydia and Sample DNA Extraction}

Cell culture of chlamydiae on coverslips and determination of inclusion forming units (IFUs) by staining with fluorescein isothiocyanate (FITC)-conjugated monoclonal antibody against chlamydial lipopolysaccharide (LPS) followed the procedure described before $(2,4,10)$. DNA extraction from 100 $\mu \mathrm{L}$ dilutions of purified elementary bodies of $C$. psittaci B577 or C. pneumoniae CDC/CWL-029 or from $20 \mu \mathrm{L}$ $10 \%$ mouse lung tissue suspension was performed with the High Pure PCR Template Preparation Kit (Roche Molecular Biochemicals), following the manufacturer's instructions. DNA was eluted in $400 \mu \mathrm{L} 10 \mathrm{mM}$ Tris- $\mathrm{HCl}, \mathrm{pH}$ 8.5 , elution buffer.

\section{RESULTS AND DISCUSSION}

\section{Optimization of Microvolume Glass Capillary PCR}

Before specific applications, we established robust generic conditions for real-time quantitative PCR with fluorescent detection in the LightCycler format, which employs glass reaction vessels and rapid temperature changes (14). The conditions indicated in Materials and Methods represent the results of the optimization of the following parameters: $\mathrm{pH}$ of PCR buffer, concentrations of $\mathrm{MgCl}_{2}, \mathrm{KCl}$, nonionic detergents, BSA, nucleotides, primers, probes, SYBR Green, Platinum Taq DNA polymerase, uracil-N-glycosylase, and thermal cycling and fluorescence acquisition conditions. We have used these methods in more than 20 different PCRs including RT-PCRs. If the primers/probes are designed according to accepted standard criteria (9) (Mfold program Web site: http://www.ibc. wustl.edu/ zuker) to amplify a target of $100-400 \mathrm{bp}$, it is typically not necessary to adjust the PCR buffer conditions, in particular magnesium concentration, aside from thermal cycling parameters.

During optimization, it became clear that quantitative PCR required extremely robust reaction parameters to be reliable not only for detection but also for accurate quantification of the target. We found, in particular, that nonionic detergents and BSA were indispensable, as was a sufficient background of unrelated DNA. While the PCR was relatively insensitive to a $\mathrm{pH}$ higher than 8.4, a $\mathrm{pH}$ lower than 8.3 resulted in strongly decreased amplification efficiency. This explains the critical need for highly pure sample DNA dissolved in a buffer with a $\mathrm{pH}$ of approximately 8.5 and the consistent use of identical buffer and volume for samples and standards in quantitative PCR. The use of hot-start Platinum Taq DNA polymerase at 1 $\mathrm{U} / 20 \mu \mathrm{L}$ reaction was also critical for reliable results. For consistent results, it was also important to prepare the master mixture just before use from separate stock solutions of enzymes, com bined nucleotides, combined primers and probes, and PCR buffer combined with BSA (and SYBR Green, for SYBR Green PCR only). Frozen aliquots of mastermixtures, even without enzymes, rapidly degraded and gave poor quantitative results.

Lack of potassium resulted in increased SYBR Green fluorescence and reduced primer dimer formation, but also reduced amplification efficiency and hybridization probe fluorescence. $\mathrm{KCl}$ at $10 \mathrm{mM}$ and $\mathrm{MgCl}_{2}$ at $3 \mathrm{mM}$ in SYBR Green PCR provided for an optimal balance between amplification efficiency, nonspecific product accumulation, and SYBR Green fluorescence. In the hybridization probe PCR formats, the concentration of $\mathrm{KCl}$ at 50 $\mathrm{mM}$ and of $\mathrm{MgCl}_{2}$ at $4.5 \mathrm{mM}$ reflect the reduced need for avoidance of non- 


\section{Research Report}

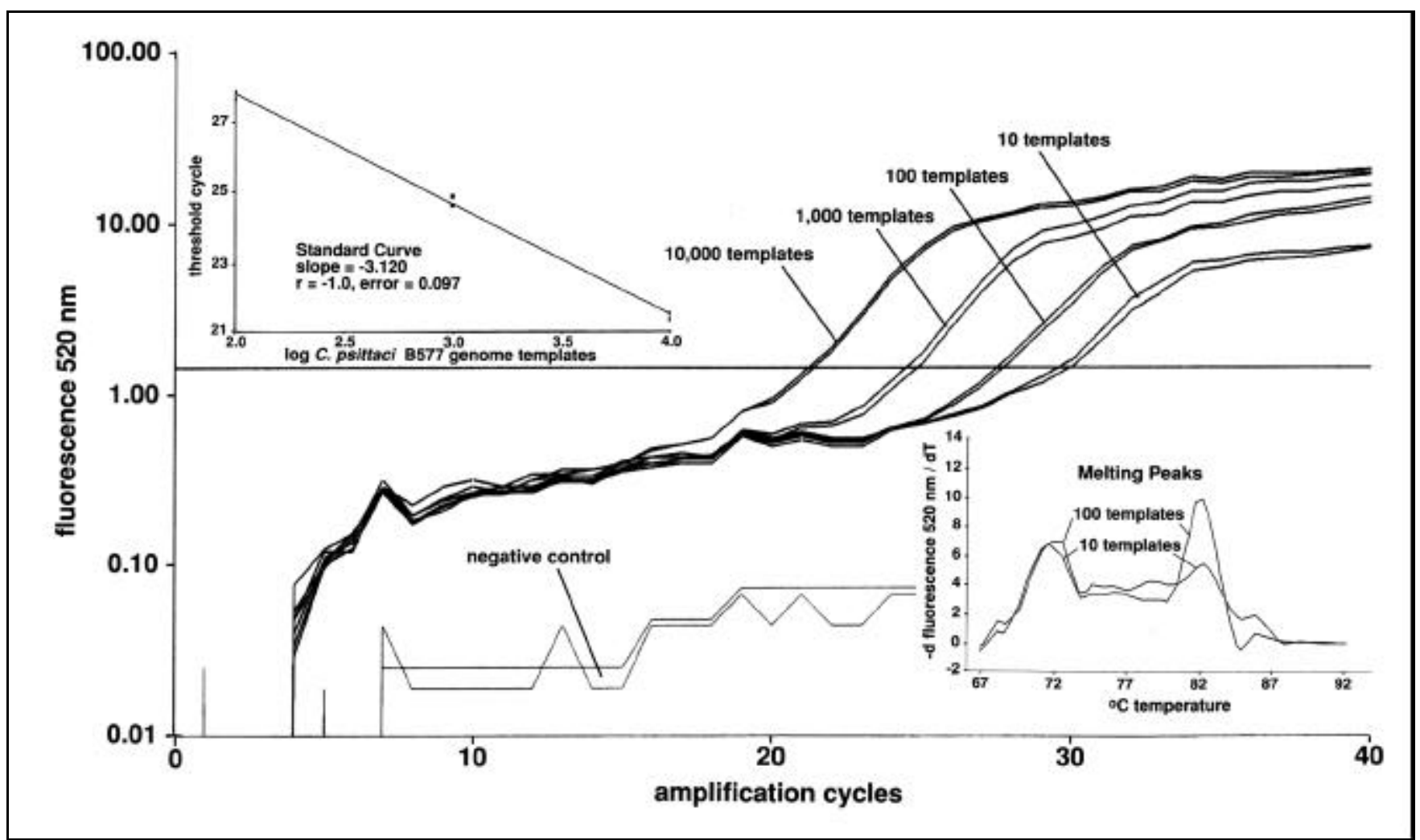

Figure 1. Chlamydia omp1 SYBR Green PCR. Fluorescence emission curves of the duplicate $C$. psittaci B577 standard DNAs at concentrations of $10^{4}-10$ template copies per PCR are displayed with the noise band. Melting curves of a 100 and a 10 template PCR in the lower right corner show the melting point of the primer dimer at approximately $72^{\circ} \mathrm{C}$, of the specific product at approximately $82^{\circ} \mathrm{C}$, and an additional melting peak in the 10 template reaction at approximately $86^{\circ} \mathrm{C}$. At the $80^{\circ} \mathrm{C}$ fluorescence acquisition temperature, the signal of the 10 template PCR becomes positive too early because of the additional signal from the $86^{\circ} \mathrm{C}$ peak. Therefore, the standard curve in the upper left corner is constructed from the 10000,1000 , and 100 template PCRs only, and data for low er template copies are obtained by interpolation between the 100 and 10 template standards. The intra-assay coefficient of variation is $15 \%$.

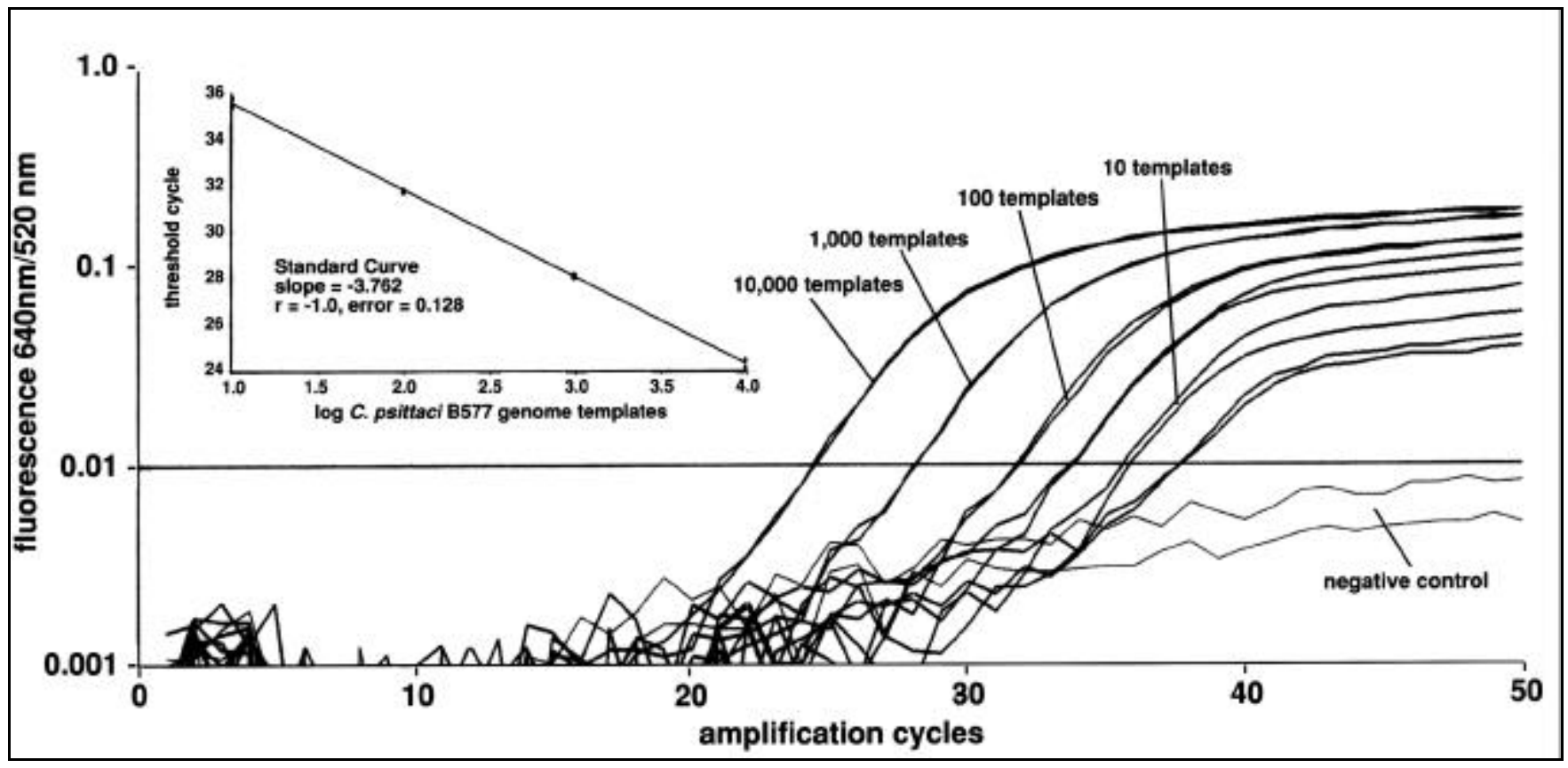

Figure 2. C. psittaci B577 FRET PCR. The FRET format in the $640 \mathrm{~nm}: 520 \mathrm{~nm}$ fluorescence ratio display resulted in highest accuracy of the log-linear standard curve for all template concentrations. Duplicates of DNA samples from mouse lungs are presented between the 100 and 10, and after the 10 template standards, respectively. The intra-assay coefficient of variation is $10.5 \%$. 
specific PCR products coupled with the increased probe fluorescent signal under these conditions.

It is noteworthy that a substantial amount of primer dimer could always be observed in the SYBR Green PCR format (Figure 1). This is in contrast to several commercial PCR buffers, which in our hands produced little or no primer dimer. However, conditions of the commercial buffers appeared to negatively affect specific amplification efficiency as well, because PCRs using these buffers typically required 5-10 more cycles to reach the threshold cycle for $10^{4}$ target molecules than those using our optimized buffer.

\section{SYBR Green PCRs}

Figure 1 represents a typical amplification plot of the Chlamydia ompl PCR using SYBR Green detection of the $C$. psittaci $\mathrm{B} 577$ product. Tenfold serial dilutions of purified C. psittaci B577 genomic DNA were used as standards, from a starting concentration of $10^{4}$ copies per PCR down to 10 copies. As is evident from the noise band at approximately 1.5 fluorescence units, the negative control remained below this cutoff even after 50 cycles of amplification. All duplicate C. psittaci B577 DNA standards are truly positive, each displaying a fluorescent signal clearly separated from that of the negative control. The slope of the signal increase over cycle number is virtually identical for all standards, indicating that the amplification efficiency remains unchanged during the critical first 35 PCR cycles. The threshold cycle distance between $10^{4}$ and $10^{3}$, and between $10^{3}$ and $10^{2}$, templates is approximately 3.2 , while the distance between the $10^{2}$ and 10 template threshold cycles is about 2.2. At 10 templates, the melting curve insert in Figure 1 indicates aberrant amplification products with a $\mathrm{T}_{\mathrm{m}}$ of approximately $86^{\circ} \mathrm{C}$ aside from the specific product with a $\mathrm{T}_{\mathrm{m}}$ of approximately $82^{\circ} \mathrm{C}$. No such aberrant products appear in the 100 template PCR. Since the fluorescence signal of the Chlamydia ompl PCR is acquired at $80^{\circ} \mathrm{C}$, such aberrant products falsely increase the signal at low template numbers, resulting in an inaccurate standard curve. To remediate this shortcoming, we constructed the standard curve for samples with more than 100 target copies from the $10^{4}, 10^{3}$, and $10^{2}$ template stan-

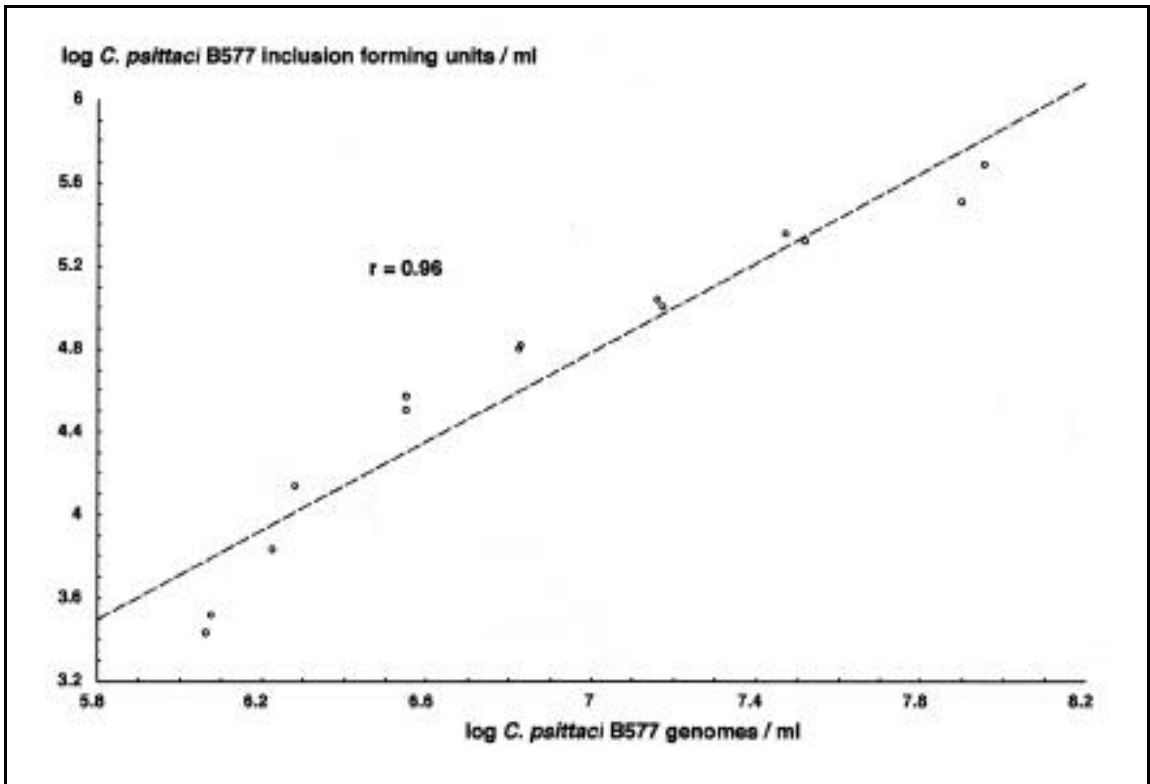

Figure 3. Linear regression analysis of $C$. psittaci B577 quantification by cell culture and $C$. psittaci B577 FRET PCR. C. psittaci B577 stock was twofold serially diluted from 1:10000 to 1:640 000. These dilutions were analyzed by both assays as described in Materials and Methods. Corresponding results were plotted, and the least square linear regression was calculated. The intra-assay coefficient of variation for the cell culture determination is $16.1 \%$, as compared to the more accurate FRET PCR with $10.5 \%$ intra-assay variation. Major deviation from linearity at both extremes of the dilution series is caused mainly by the nonlinearity of the cell culture assay.

dards. This resulted in a linear threshold cycle versus log template copies standard curve (standard curve insert in Figure 1), while we interpolated between the $10^{2}$ and 10 standards for samples with less than 100 target copies.

The problem with a false signal increase at low template numbers was absent in PCRs of the human COX-1 tem plate with a product containing $58 \%$ GC. The approximately $90^{\circ} \mathrm{C} \mathrm{T}_{\mathrm{m}}$ of the specific amplification product allowed the acquisition of SYBR Green fluorescence at $87^{\circ} \mathrm{C}$. At this temperature, nonspecific products are melted and thus do not bind SYBR Green any more and do not contribute to the fluorescent signal. This results in equal spacing of the signal curves for all standards and a linear standard curve between $10^{4}$ and 10 template copies (data not shown).

To confirm the Chlamydia genus specificity of the SYBR Green PCR, we successfully amplified and quantified with similar accuracy purified $C$. pneumoniae DNA and amplified the ompl locus of DNA isolated from cell culture harvests of $C$. trachomatis serovar A and C. pecorumLW613 cultures. Limiting dilution analysis of multiple replicate PCRs of $C$. psittaci B577 and C. pneumoniae CDC/CWL029 standards exhibited a Poisson distribution of positive and negative results when the dilution of the standard approached or exceeded a theoretical number of one or less template copies per $5 \mu \mathrm{L}$ PCR input. These data demonstrated that the quantitative PCR format in fact detected single copies of input templates.

\section{FRET PCRs}

Using the target of the Chlamydia omp1 SYBR Green PCR, we established a dual probe FRET PCR, which generated the signal by FRET. The PCR as shown in Figure 2 is specific for $C$. psittaci B577. However, the degenerate LCR-640-labeled probe CHLANPR hybridizes to all known chlamydial ompl sequences. For detection of different chlamydial strains, it is therefore sufficient to replace the fluorescein-tagged B577PR with another cognate, similarly fluorescein-labeled probe. Using this approach, we gener- 
ated equally functional FRET PCRs for strains of the three other chlamydial species (Table 1) as well. The FRET format was evaluated similar to the SYBR Green PCR. Again, the FRET PCRs allowed for linear quantification of chlamydiae down to single copies of the input template, without relative overamplification at low template num bers (Figure 2).

The FRET format in positive sam ples resulted in absolute enhanced LightCycler Red 640 emission (F2, 640 $\mathrm{nm})$, as well as an increased ratio of $640 \mathrm{~nm}$ to fluorescein $(\mathrm{F} 1,520 \mathrm{~nm})$ emission. This second readout was comparable to an internal reference dye format and thus rendered the result independent of variations in absolute fluorescence. In our hands, the FRET PCR format was by far the most robust and consistent method. In the FRET PCRs, it was important to place the probes at least $60 \mathrm{bp}$ downstream of the primer annealing to the same DNA strand, and to acquire fluorescence within $3 \mathrm{~s}$ of equilibration at the annealing temperature. Violation of these parameters resulted in delays in signal appearance of up to 10 cycles, presumably because the Taq DNA polymerase displaced one or both probes.

An advantage of the various formats of the PCRs is that the genus-specific Chlamydia ompl PCR can be used for screening of samples by the inexpensive SYBR Green detection method. If desired, the FRET PCR format can then be used to more accurately quantify chlamydiae in positive samples, particularly those with low copy numbers. Also, the increased specificity of the probe format may be used to confirm SYBR Green PCR results and for strain-specific typing. FRET is advantageous over other hybridization-based detection formats of the products because the probes carry single fluorescent labels and are easier to synthesize than TaqMan $^{\circledR}$ probes (Applied Bio- systems, Foster City, CA, USA) (3). Furthermore, the time-consuming optimization of probe folding, which is necessary for molecular beacons or scorpion primers, is typically not required for FRET probes $(11,12,13)$.

\section{Correlation between PCR and Cell Culture Quantification of C. psittaci B577}

Pre-PCR sample DNA extraction was the single most critical parameter for absolute quantification of chlamydiae in samples. We evaluated the percent recovery of DNA by adding known copy numbers of COX-1 template before extraction and found that glass matrix binding and elution of sample DNA resulted in high recovery of DNA without PCR inhibitors. As calculated from COX-1 PCRs, typically $85 \%-95 \%$ of sample DNA was recovered. If DNA was extracted in one batch per experiment, recovery was consistently high 
enough that normalizing to $100 \%$ DNA recovery was unnecessary.

We first examined the correlation between chlamydial cell culture and $C$. psittaci B577 FRET PCR by analyzing serial dilutions of purified $C$. psittaci B577 elementary body stock by both methods. As evident in Figure 3, there was a linear correlation $(\mathrm{r}=0.96, P<$ 0.0008 ) in this log-log regression plot between chlamydial IFUs and chlamydial genomes found for the serial dilutions (1:10000-1: 640000$)$ by cell culture and PCR, respectively. The regression plot reveals that the correlation is weakest at both extremes of the dilution series and that the deviations mainly result from nonlinearity of the cell culture quantification. An interesting result is the fact that these data demonstrate that only approximately $0.5 \%$ of all chlamydial elementary bodies were infectious.

We then evaluated cell culture versus PCR determination in 24 homogenized mouse lungs infected with $C$. psittaci B577. Not unexpectedly for animal infection specimens, the correlation between the methods was lower. The correlation coefficient between IFUs and C. psittaci B577 FRET PCR was higher (r $=0.90, P<0.0004)$ than for the Chlamydia ompl SYBR Green PCR ( $\mathrm{r}$ $=0.85, P<0.002$ ). Background interference was the actual factor limiting the sensitivity of both the Chlamydia omp1 SYBR Green PCR and $C$. psittaci B577 FRET PCR to $4 \times 10^{3}$ chlamydial genomes/100 mg lung tissue. This is, however, about 15-fold more sensitive than cell culture quantification, which has, in our hands, a practical limit of $6 \times$ $10^{4} \mathrm{IFU} / 100 \mathrm{mg}$ tissue.

Collectively, these results demonstrate that the FRET and SYBR Green quantitative PCR methods can successfully and reliably replace many aspects of the cell culture method for chlamydial quantification. We envision that these fluorescent techniques will make PCR the method of choice for diagnostic and quantitative detection of chlamydiae.

\section{ACKNOWLEDGMENTS}

We thank Dave Schuster and Subbu Dharmaraj for helpful discussions. This study was supported by grants from
Bayer AG and the National Institutes of Health (AI 38977) to B.K.

\section{REFERENCES}

1.An, Q., J. Liu, W. O'Brien, G. Radcliffe, D. Buxton, S. Popoff, W. King, M. Vera-Garcia et al. 1995. Comparison of characteristics of Q beta replicase-amplified assay with com petitive PCR assay for Chlamydia trachomatis. J. Clin. Microbiol. 33:58-63.

2.Frost, E.H., S. Deslandes, D. BourgauxRamoisy, and P. Bourgaux. 1995. Quantitation of Chlamydia trachomatis by culture, direct immunofluorescence and competitive polymerase chain reaction. Genitourin. Med. $71: 239-243$.

3.Holland, P.M., R.D. Abramson, R. Watson, and D.H. Gelfand. 1991. Detection of specific polymerase chain reaction product by utilizing the $5^{\prime}-3^{\prime}$ exonuclease activity of Thermus aquaticus DNA polymerase. Proc. Natl. Acad. Sci. USA 88:7276-7280.

4.Huang, J., M.D. Wang, S. Lenz, D. Gao, and B. Kaltenboeck. 1999. IL-12 administered during Chlamydia psittaci lung infection in mice confers immediate and long-term protection and reduces macrophage inflammatory protein-2 level and neutrophil infiltration in lung tissue. J. Immunol. 162:2217-2226.

5.Ishiguro, T., J. Saitoh, H. Yawata, H. Yam agishi, S. Iwasaki, and Y. Mitoma. 1995. Homogeneous quantitative assay of hepatitis $\mathrm{C}$ virus RNA by polymerase chain reaction in the presence of a fluorescent intercalater. Anal. Biochem. 229:207-213.

6.Kaltenboeck, B., K.G. Kousoulas, and J. Storz. 1993. Structures of and allelic diversity and relations among the major outer mem brane protein (ompA) genes of the four chlamydial species. J. Bacteriol. 175:487-502.

7.Kaltenboeck, B., N. Schmeer, and R. Schneider. 1997. Evidence for numerous ompl alleles of porcine Chlamydia trachomatis and novel chlamydial species obtained by PCR. J. Clin. Microbiol. 35:1835-1841.

8.Nazarenko, I.A., S.K. Bhatnagar, and R.J. Hohman. 1997. A closed tube format for am plification and detection of DNA based on energy transfer. Nucleic Acids Res. 25:25162521.

9.SantaLucia, J., Jr. 1998. A unified view of polymer, dumbbell, and oligonucleotide DNA nearest-neighbor thermodynamics. Proc. Natl. Acad. Sci. USA 95:1460-1465.

10.Stamm, W.E., M. Tam, M. Koester, and L. Cles. 1983. Detection of Chlamydia trachomatis inclusions in McCoy cell cultures with fluorescein-conjugated monoclonal antibodies. J. Clin. Microbiol. 17:666-668.

11.Tyagi, S. and R.F. Kramer. 1996. Molecular beacons: probes that fluoresce upon hybridization. Nat. Biotechnol. 14:303-308.

12.Whitcombe, D., J. Theaker, S.P. Guy, T. Brown, and S. Little. 1999. Detection of PCR products using self-probing amplicons and fluorescence. Nat. Biotechnol. 17:804807.

13.Wittwer, C.T., M.G. Herrmann, A.A. Moss, and R.P. Rasmussen. 1997. Continuous fluo- rescence monitoring of rapid cycle DNA am plification. BioTechniques 22:130-138.

14.Wittwer, C.T., K.M. Ririe, V.R. Andrew, D.A. David, R.A. Gundry, and U.J. Balis. 1997. The LightCycler ${ }^{\mathrm{TM}}$ : a microvolume multisample fluorimeter with rapid temperature control. BioTechniques 22:176-181.

Received 3 February 2000; accepted 10 August 2000.

\author{
Address correspondence to: \\ Dr. Bernhard Kaltenboeck \\ Department of Pathobiology \\ College of Veterinary Medicine \\ Auburn University \\ Auburn, AL 36849-5519, USA. \\ e-mail:kaltebe@auburn.edu
}

